\title{
Economia Solidária, Saúde Mental e a prática do terapeuta ocupacional: relatos de participantes de um grupo de geraçáo de trabalho e renda ${ }^{1}$
}

\author{
Luís Felipe Ferro ${ }^{\mathrm{a}}$, Mônica de Macedo ${ }^{\mathrm{a}}$, Morgana Bardemaker Loureiro ${ }^{\mathrm{b}}$

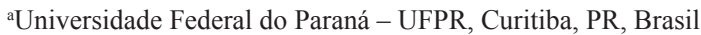

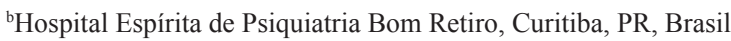

\begin{abstract}
Resumo: O reposicionamento da atenção em Saúde Mental no Brasil propõe suporte ao usuário em diversos equipamentos territoriais. A inclusão no trabalho vem sendo discutida na política pública de saúde mental, sendo notável a proliferação de grupos de geração de trabalho e renda (GGTR) e cooperativas. Buscou-se aqui explorar potencialidades e dificuldades de um GGTR que produz bolsas a partir de banners, fundamentado nos pressupostos da Economia Solidária (ES), fruto de parceria entre o Departamento de Terapia Ocupacional da Universidade Federal do Paraná e a Associação Arnaldo Gilberti. Como método, realizaram-se reflexões advindas do relato crítico da experiência própria de participação por três anos junto a um GGTR, apoiadas em argumentações que tomam como base a realização de pesquisa de campo exploratória, qualitativa. A coleta de dados utilizou entrevistas não estruturadas focalizadas, com participação de oito sujeitos frequentadores do GGTR há pelo menos seis meses. A análise de dados constituiu-se de exame, categorização, tabulação e recombinação das evidências, utilizando-se análise hermenêutica dialética. A partir daí compuseram-se quatro categorias: Economia Solidária, inclusão social e autogestão: Aberturas na percepção dos usuários; Pragmática do GGTR em Saúde Mental: Estratégias para o fortalecimento da iniciativa; Geração de trabalho e renda: Entre encaminhamentos e a estruturação concisa de Projetos Terapêuticos Singulares; Economia Solidária e o GGTR: Entre fortalecimento e ideologia. Os resultados desta investigação apontam a necessidade de ações de diversas ordens para fazer de conceitos como inclusão social e solidariedade pragmáticas cotidianas.
\end{abstract}

Palavras-chave: Economia Solidária, Terapia Ocupacional, Saúde Mental, Reabilitação Psicossocial, Cooperativismo.

\section{Solidarity Economy, Mental Health and the practice of occupational therapists: reports of participants of a group to generate work and income}

\begin{abstract}
The repositioning of mental health care in Brazil proposes actions for user support in a variety of territorial attention equipment. Labor inclusion has been widely discussed in mental health public policy, with remarkable proliferation of groups of work and income generation and cooperatives to serve this population. This article seeks to explore the potential and difficulties of an income generation group which produces bags with reused banners, based on the assumptions of Solidarity Economy, born with the partnership between the Occupational Therapy Course of the Federal University of Paraná and 'Arnaldo Gilberti' Association. The present study uses a dual methodological approach: a critical case report of the three-year experience with this income generation group; and a qualitative exploratory field research. Data was collected through unstructured interviews applied to eight subjects who had attended the income generation group for at least six months. Data analysis consisted of examining, categorizing, tabulating and recombining the evidence, using hermeneutic dialectic analysis. Four categories were identified: Solidarity Economy, social inclusion and self-management: opening of the perception of users; Pragmatics of the Work and Income Generation Group in Mental Health: strategies for strengthening the initiative; Work and Income
\end{abstract}

Autor para correspondência: Luís Felipe Ferro, Universidade Federal do Paraná, Campus Botânico, Prédio da Terapia Ocupacional e Enfermagem, Av. Prefeito Lothário Meissner, 632, Bairro Jardim Botânico, CEP 80210-170, Curitiba, PR, Brasil, e-mail: luisfelipeferro@ gmail.com Recebido em Fev. 10, 2014; $1^{\text {a }}$ Revisão em Ago. 14, 2014; Aceito em Set. 17, 2014. 
Generation: between referrals and the concise structuring of Singular Therapeutic Projects; Solidarity Economy and the work and income generation group: between empowerment and ideology. The results of this research reveal that actions must be taken to pragmatize concepts such as social inclusion and solidarity.

Keywords: Solidarity Economy, Occupational Therapy, Mental Health, Psychosocial Rehabilitation, Cooperativism.

\section{Introdução}

A atual política pública brasileira de saúde mental, em detrimento das práticas de exclusão próprias ao modelo manicomial, propóe a estruturação de diferentes equipamentos voltados a proporcionar suporte ao usuário e familiares em seu cotidiano, aliando acompanhamento clínico a açóes que promovam sua inclusão social (BRASIL, 2004a, 2011b). Nesse contexto, Centros de Atenção Psicossocial, Unidades de Acolhimento, Consultórios na Rua, Leitos e Unidades Psiquiátricas em Hospitais Gerais, Centros de Convivência, Estratégia de Saúde da Família, Núcleos de Apoio à Saúde da Família, acompanhamentos terapêuticos, grupos de convivência, grupos de geração de trabalho e renda etc. tomaram lugar, oferecendo atenção territorial à sua população alvo (BRASIL, 2011a; FERRO et al., 2012; LOPES; LEĀO, 2002; FONSECA, 2008).

Tal reposicionamento proporcionou o desvelamento de amplas possibilidades de intervenção, antes acortinadas pelo manicômio. Diversos determinantes sociais no processo de saúde-doença passaram a ser vislumbrados, impondo ao profissional da saúde a necessidade de elaboração de novas estratégias e açôes. Condiçôes de moradia, saneamento básico, educação, lazer, acesso a serviços essenciais, renda e trabalho são tomados como condiçóes sine qua non para a compreensão do sofrimento psíquico e para compor as intervençōes em Saúde Mental (BRASIL, 2011b, 2012).

Um dos pilares da atual política pública de saúde mental é o investimento em projetos que proporcionem subsídios para inclusão no trabalho (BRASIL, 2006, 2011a). Grupos de geração de trabalho e renda e cooperativas vêm proliferando com marcante expressão no campo da Saúde Mental, procurando propor linha de fuga para enfrentar as diversas dificuldades vivenciadas por pessoas com transtorno mental junto ao mercado de trabalho formal (LUSSI; MATSUKURA; HAHN, 2010; RIBEIRO; OLIVEIRA, 2005; MARTINS, 2009).

A partir desse panorama, o departamento de Terapia Ocupacional da Universidade Federal do Paraná (UFPR), por meio da parceria de estágios curriculares em Saúde Mental com a Associação Arnaldo Gilberti, estruturou em 2008 um grupo de geração de trabalho e renda com foco na inclusão social da pessoa com transtorno mental.

É intenção do material que se apresenta dar corpo à apresentação crítica do relato de experiência de três anos de realização do grupo. Para dar suporte a tal empreitada, compusemos, em adição, uma pesquisa de campo para explorar as dificuldades e potencialidades da iniciativa, segundo a perspectiva de seus usuários.

\section{Métodos}

O presente artigo é vinculado ao projeto Acolhimento Enquanto Ferramenta Estratégica para a Estruturação de Propostas de Geração de Trabalho e Renda em Saúde Mental, aprovado pelo Comitê de Ética em Pesquisa (CEP/UFPR) sob o número 1074.199.10.12.

Este manuscrito toma como base argumentativa a congregação entre o relato da experiência de três anos na realização de um grupo de geração de trabalho e renda e os relatos de seus participantes, obtidos por meio de pesquisa de abordagem qualitativa (MINAYO, 2003).

A partir de uma pesquisa de campo exploratória conduzida em 2011 foram realizadas entrevistas não estruturadas focalizadas (MARCONI; LAKATOS, 2007) com oito sujeitos participantes de um Grupo de Geração de Renda. Todas as entrevistas foram gravadas e transcritas.

Como critério de inclusão, os sujeitos deveriam estar vinculados ao grupo há seis meses ou mais. A pesquisa aconteceu com o consentimento expresso dos usuários, obtido a partir da leitura e assinatura do Termo de Consentimento Livre e Esclarecido. Cinco entrevistados são mulheres e três são homens, residentes da cidade de Curitiba ou regiẫo metropolitana.

Para a análise do material, realizaram-se os seguintes procedimentos, conforme proposto por Yin (2010): exame; categorização; tabulação; e recombinação das evidências. A matriz estrutural utilizada para a análise dos dados foi a análise hermenêutico-dialética. 
Antes da apresentação pormenorizada dos dados, contudo, procurar-se-á contextualizar de maneira mais detalhada o grupo de geração de renda, assim como realizar-se uma apresentação da Economia Solidária, suporte teórico e organizacional do grupo, de maneira a proporcionar subsídios para a discussão crítica de sua pragmática.

\section{Terapia Ocupacional e a Associação Arnaldo Gilberti: Grupo de Geração de Trabalho e Renda em foco}

Tendo como pano de fundo o modelo proporcionado pela Reabilitação Psicossocial, estruturamos as disciplinas curriculares de estágio de observação e prática para proporcionar ações, realizadas por docente e estagiários do Departamento de Terapia Ocupacional da UFPR, na direção de promover a inclusão social de pessoas com transtorno mental. A necessidade eminente de enfrentamento da exclusão dessas pessoas do mercado de trabalho formal mobilizou tais agentes a instaurar, em 2008, espaços de geração de trabalho e renda.

Para sua pragmatização, o grupo de geração de trabalho e renda apresenta parceria com a Associação Arnaldo Gilberti, localizada na cidade de Curitiba. A Associação Arnaldo Gilberti (AAG) é uma entidade filantrópica, fundada em 1994, com a intenção de proporcionar atendimento e defesa dos direitos de pessoas com transtorno mental. Atualmente recebe auxílio da prefeitura de Curitiba para sua subsistência, contando com verba para pagamento de contas de água, luz, telefone e aluguel.

As açôes, grupos e atividades proporcionadas pela AAG são realizadas em sua maioria por voluntários e por meio da parceria com o departamento de Terapia Ocupacional da UFPR. A Associação ainda gerencia dois Serviços Residenciais Terapêuticos, através de parceria com a prefeitura de Curitiba.

Inicialmente, o grupo reunia-se duas a três vezes por semana e cada encontro tinha duração média de 3-4 horas. A iniciativa tem como produto final bolsas de banners reutilizados: atualmente, a frequência dos encontros do grupo pauta-se pelas suas encomendas, chegando o grupo a se encontrar todos os dias da semana. Todas as bolsas e pastas são individualizadas e produzidas artesanalmente.

Antes de adentrar propriamente na análise do material advindo das entrevistas, em sua relação com o relato da experiência profissional vivenciada, é necessária breve contextualização do guia metodológico e filosófico que pauta as açôes da Terapia Ocupacional junto a esse grupo de Geração de Trabalho e Renda.

\section{Economia Solidária e Saúde Mental: aliança para construção da inclusão}

Transformações no mundo do trabalho ocorridas nas décadas de 1970 e 1980, advindas da crise no modelo fordista-taylorista de produçáo, do incremento tecnológico e de novas formas de gestão da produção, diminuíram exponencialmente a necessidade de mão de obra (AZAMBUJA, 2009; SILVA; OLIVEIRA, 2009). Em adiçáo, possibilidades de reposicionamento de unidades de trabalho para locais que permitissem contrataçấo de mão de obra a baixo custo agregaram-se a este quadro aumentando o

desemprego em praticamente todo o mundo, especialmente em países centrais como Estados Unidos e Inglaterra. Essa situação é agravada pelas duas crises do petróleo da década de 1970, pelas dificuldades de financiamento do Estado de Bem-Estar Social na Europa ocidental e pela adoção de políticas econômicas neoliberais (SILVA; OLIVEIRA, 2009, p. 60).

Em contexto brasileiro, as crises do trabalho vivenciadas na década de 1980 proporcionam terreno para a edificação de movimentos diversos.

De fato, é no quadro atual de crise do trabalho assalariado que os estudiosos começaram a detectar desde os anos de 1980, mas especialmente a partir da década seguinte, um conjunto de movimentos empunhados por trabalhadores que perderam seu emprego e que náo conseguiram se reinserir no mercado de trabalho ou, ainda, por aqueles que sempre viveram na informalidade. Centrando-se, especialmente, na formaçáo de cooperativas de trabalho e de produção e de associações de trabalhadores, nas quais se busca a autogestão, tais experiências vêm sendo reconhecidas sob o nome de Economia Solidária (LEITE, 2009, p. 32).

Tal quadro proporcionou a proliferação e consolidação de cooperativas de trabalho diversas, tomando corpo, inicialmente na França e no Brasil, 
com maior ênfase na década de 1990, a proposta da Economia Solidária.

Diferentes movimentos sociais e equipamentos passaram a edificar o cooperativismo e a Economia Solidária no contexto brasileiro, ênfase dada ao Movimento dos Trabalhadores Rurais Sem Terra (MST); Central de Cooperativas e Empreendimentos Solidários (UNISOL); Sindicato dos Metalúrgicos do ABC; a Agência de Desenvolvimento Solidário (ADS) da Central Única dos Trabalhadores (CUT); diferentes organizaçôes não governamentais; categorias e entidades sindicais; apoio de congregaçóes religiosas, associaçôes e pastorais, como Cáritas; Incubadoras Tecnológicas de Cooperativas Populares (COUTINHO et al., 2005; SOUSA, 2007, 2008).

Em junho de 2003 realizou-se a III Plenária Brasileira de Economia Solidária, que contou com um processo preparatório de mobilização em 17 estados e teve a participaçáo de 900 pessoas de diversas partes do país. Foi nesse evento que foi criada, de forma definitiva, a denominação Fórum Brasileiro de Economia Solidária (FBES). [...] O FBES saiu dessa III Plenária com a incumbência de articular e mobilizar as bases da Economia Solidária pelo país em torno da Carta de Princípios e da Plataforma de Lutas aprovadas naquela oportunidade. [...] Outro fruto decorrente daquele evento foi o desencadeamento da criação dos fóruns estaduais e regionais que puderam garantir, por sua vez, a realização do I Encontro Nacional de Empreendimentos de Economia Solidária com trabalhadoras/es advindos de todos os estados. Esse encontro teve um total de 2.500 pessoas e aconteceu nos dias 13, 14 e 15 de agosto de 2004 (FÓRUM..., 2014).

Marco importante, ainda, é a transformação da Economia Solidária em política pública através da criação, em 2003, no governo Lula, da Secretaria Nacional de Economia Solidária (SENAES), vinculada ao Ministério do Trabalho e Emprego (LEITE, 2009; BRASIL, 2003, 2004b).

A Economia Solidária (ES), nesse cenário, proporciona marcos conceituais, legislativos e filosóficos que oferecem base estrutural para diversas iniciativas de geração de trabalho e renda. Advogando junto à defesa de modos solidários de convivência, a ES propóe funcionamento social alternativo ao capitalista, pautado em valores de cidadania, cooperação, igualdade e democracia, com vistas a proporcionar inclusão social às diferentes populaçôes (AZAMBUJA, 2009).
A Economia Solidária (ES) versa a respeito de uma nova ordem e funcionamento social, na direção da construção de possibilidades de trabalho, geração de renda e convivência em um mundo permeado por valores solidários.

A economia solidária é a resposta organizada à exclusão pelo mercado, da parte dos que não querem uma sociedade movida pela competição, da qual surgem incessantemente vitoriosos e derrotados. É, antes de qualquer coisa, uma opção ética, política e ideológica, que se torna prática quando os optantes encontram os de fato excluídos e juntos constroem empreendimentos produtivos, redes de troca, instituiçóes financeiras, escolas, entidades representativas etc. que apontam para uma sociedade marcada pela solidariedade, da qual ninguém é excluído contra a vontade (SINGER, 2005, p. 11).

Enquanto estrutura organizacional, propóe grupos, cooperativas, coletivos de trabalho, organizados de maneira democrática em seu processo decisório e orientados por características como autonomia, solidariedade, participação, consenso, responsabilidade, equidade e ajuda mútua. Castanheira e Pereira (2008, p. 120-121) apontam como diretrizes da economia solidária:

[a] igualdade de direitos e de condiçóes materiais, tendo como condição a coletivização dos meios de produçáo; [a] democracia deliberativa, náo se manifestando a hierarquia no processo decisório; [a] condição de sujeito dos indivíduos que participam da ação, pois se considera que são portadores da consciência crítica nos processos sociais, produtivos e econômicos; [o] nível pleno de participação, sem a divisão do trabalho entre concepção e execução, manifestando-se apenas a coordenação do processo de trabalho como forma cooperativa de organização; [os] vínculos sociais baseados na confiança e na solidariedade.

Em nível microestrutural, propusemos o grupo de geração de trabalho e renda com base nesses princípios organizacionais e filosóficos, contudo, embora a aplicação pragmática apresente diversas potencialidades, é, também, impregnada por severos desafios.

\section{Análise de dados}

A partir das análises das oito entrevistas, foram criadas quatro categorias na direçáo 
de proporcionar, como premedita a análise hermenêutico-dialética, um prisma sobre um percurso individual dos usuários junto ao grupo, suas percepçôes e acepçóes, assim como uma reflexão sobre a prática do terapeuta ocupacional e uma visada ampla sobre a Economia Solidária que, embora de maneira macroestrutural, influencia diretamente no cotidiano concreto do grupo de geração de trabalho e renda.

No texto que se segue apresentaremos as falas dos sujeitos da pesquisa, que terão seus nomes substituídos pela letra $S$, seguido de um número.

\subsection{Economia Solidária, inclusão social e autogestão: reflexões sobre o trabalho do terapeuta ocupacional}

A fala inicial escolhida para este trabalho desvela uma realidade bastante presente no cotidiano dos usuários da Saúde Mental, acompanhada fenomenicamente por diversos profissionais da saúde. Embora com certa extensão, acreditamos que representa com propriedade o primeiro ponto a ser discutido.

S1: Eu tentei várias vezes conseguir emprego lá fora. Eu tentei, mas não dava certo... Eu levava atestado de psiquiatra e eles me mandavam embora. Eu era uma boa funcionária, mas eles me mandavam embora. Eaqui dentro começou a nascer uma força dentro de mim quando eles mexeram nisso, quando os profissionais mexeram nisso, que aqui a gente teria chance de conseguir um serviço honesto e ganhar um dinheiro mesmo que fosse pouco e ter uma dignidade, ser tratado como ser humano. Porque lá fora eu tentei vários empregos, tentei no Carrefour, no Mercadorama, tentei nas Lojas Americanas, mas, a partir do momento que eu levava atestado psiquiátrico, eles não davam "pra" mim... eles não davam pelo fato de [eu] ser uma pessoa com transtorno mental.

Grande parte dos profissionais da Saúde Mental já se deparou com usuários que relatam, como $S 1$, seu insucesso na busca por emprego. Se o sistema capitalista vem assolando e expurgando de sua rede de produção e trocas diferentes segmentos da população (CAVEDON; FERRAZ, 2006), some-se a essa problemática a presença de atestados psiquiátricos; condiçóes clínicas com momentos de instabilidade e crise (e possivelmente necessidade de afastamento por motivos de saúde); carteiras de trabalho com três, quatro, cinco... empregos com a permanência de um a três meses. Tais condiçóes influenciam substancialmente, e negativamente, a contratação do usuário dos serviços de Saúde Mental e sua vinculação ao mercado capitalista.

Ao serem escutados sobre sua percepção em vincular-se a um trabalho formal, S1, S5 e S8 relatam:

S1: Eu acho que não daria certo, porque en não estou bem. Por enquanto não estou bem, eu estou tomando 12 comprimidos por dia, eu ando muito tonta assim e não vai dar certo. S5: Gostaria de trabalhar fora em alguma coisa, mas estou pensando ainda... Eu já tive muito problema de relacionamento no trabalho, então por isso... S8: [Sem o dinheiro da aposentadoria] eu não sei o que eu faria, porque eu não aguento trabalhar.

Paul Singer e diferentes autores vinculados à Economia Solidária (CASTANHEIRA; PEREIRA, 2008; BRASIL, 2006; NARDI; YULES, 2005) acusam que cobranças acirradas, ritmos acelerados impostos aos trabalhadores, aliados a relaçóes cada vez mais competitivas, próprias do regime capitalista, notadamente compóem um movimento de exclusão de diferentes segmentos sociais, incluindo-se aqui parte da população vinculada à Saúde Mental. Defendem a necessidade de construçáo de iniciativas que possibilitem ampla inserção das mais variadas populações de uma sociedade “...da qual ninguém é excluído contra a vontade” (SINGER, 2005, p. 11).

S1: Como na doença mental, o dr. Arnaldo Gilberti já acreditava que não é só remédio, eu acho que a Terapia Ocupacional é tudo [...] é importante porque você ganha um dinheirinho, às vezes você não tem dinheiro "pra" nada e ai você ganha esse dinheirinho trabalhando dois dias por semana. É como se eu ganhasse um presente, assim, eu acho que é muito importante "pro" doente mental [...]. Essa GR aqui dentro é uma coisa que não tem explicação, é tudo "pra" mim.

A Economia Solidária procura fazer frente a esse quadro, propondo estruturação de espaços de produção e trocas sociais que, para além do lucro, instauram-se em relaçóes de solidariedade e convivência (OLIVEIRA, 2001).

S1: Eu levanto de manhã, pego ônibus com pessoas que vão trabalhar, com carteira registrada, mas eu me sinto como se fosse trabalhar com carteira registrada e venho aqui, eu faço esse trajeto e isso me dá uma força muito grande. Aqui dentro eu estou com um grupo que 
eu amo, eu estou com meus irmãos e pessoas que... os profissionais... que olham com carinho. Então eu estou trabalhando, eu estou lucrando porque tenho o carinho e a força dos profissionais e eu tenho essa irmandade que são pessoas que sentem o mesmo que eu sinto [...] é maravilhoso você sair "pra" trabalhar e ao mesmo tempo curtir essa coisa de irmandade, de estar junto com pessoas... S2: Eu converso daqui, converso dali [...] os outros dão um apoio "pra” gente, ai é muito bom, né? Fazer amizade com todos. Todo mundo é muito bacana. S4: Ah, eu vejo que as pessoas umas ajudam as outras aqui e também conversam... S7: Sou bem acolhido e trabalho bem e tudo, $e$ ainda ganho um dinheirinho "pra" mim né? "Pra se" manter [...] o pessoal é legal.

O capitalismo, como qualquer sistema econômico, não concretiza somente produtos e finanças, produz relaçôes humanas (NARDI; YULES, 2005). Em combate declarado à exclusão de segmentos sociais do mercado de trabalho (seja por fragilidade social, idade, experiência profissional etc.), perpassando por relaçóes de trabalho hierárquicas, competitivas e, por vezes, adoecedoras, próprias ao capitalismo, a Economia Solidária propóe a construção paulatina de vínculos de solidariedade pautados em valores diferentes (SINGER, 2005). As falas acima corporificam tais direcionamentos da Economia Solidária e atestam, como frutos do grupo de geração de trabalho e renda estudado, a mistura de convivência, "irmandade", apoio mútuo à produção econômica, gerando outra categoria de riquezas.

Contudo, distante de advogar por uma visão romantizada das relaçóes na Economia Solidária, interessa sim o aprofundamento em sua crítica, ressaltando-se nesse processo o papel de mediador dos apoiadores de tais empreendimentos (CIA; CORTEGOSO, 2007), função muitas vezes exercida pelo terapeuta ocupacional.

S3: Ai a gente chega no horário certo, eu nunca cheguei atrasada. O S2 também chega no horário certo, mas tem muita gente ai que chega atrasado e a gente vai lá, olha e pôs o horário certo. Eu acho errado, porque ele não pode querer ganhar nas costas dos outros. Ele está tirando dinheiro [...] na realidade. Porque se ele chegou às $10 \mathrm{~h}$, marque às $10 \mathrm{~h}$. Mas não, ele chega às 10 h e marca às $9 \mathrm{~h}$. [...] "Pra" mim isso é sem-vergonhice.

Cada um dos usuários do Grupo de Geraçáo de Renda estudado assina um livro ponto ao começar sua participação. O lucro obtido com a venda das bolsas é, então, dividido conforme as horas trabalhadas.

Essa organização, como enunciado acima, apresenta algumas dificuldades. Pelos relatos, alguns usuários tomam vantagem do funcionamento do grupo, registrando horas de acordo com interesses individuais - o que causou a repercussão evidenciada na fala anteriormente transcrita.

Uma das saídas apontadas pelo relato é a fiscalizaçáo mais rigorosa pelos terapeutas. $\mathrm{O}$ trecho que se segue apresentará alguns dados e possibilitará reflexões críticas sobre a prática do terapeuta ocupacional.

S2: Eu espero que o comando técnico, a chefia, né, seja mais rigoroso, tipo assim, às vezes o colega é mais desleixado, tem que estar mais ali em cima, e estar focando... Às vezes tem três ali que não querem fazer, não é a gente que vai falar, é a chefia. Eles devem estar um pouco mais atentos ali para ver aquela pessoa.

A fala é emblemática e incita questionamentos. O terapeuta ocupacional, muitas vezes integrante e/ ou apoiador de grupos de geração de renda, presente em parte considerável dos Centros de Atenção Psicossocial (CAPS), atualmente, equilibra-se numa corda bamba de funçóes frequentemente conflitantes.

Uma das diretrizes estruturais da Economia Solidária é a autogestão igualitária e democrática por seus membros (MARTINS, 2009). O relato acima, embora advindo de um único e mais recente sujeito do grupo, reforça um ponto estratégico que deve estar sempre presente nas reflexôes dos terapeutas ocupacionais: a necessidade de formação para Economia Solidária, insistentemente reiterada por diferentes autores (SINGER, 2001; COUTINHO et al., 2005; TALEIKIS, 2009). A verticalidade própria ao chefe capitalista, é diluída - e deve ser! - no empreendimento de bases solidárias. Contudo, exemplos, vivências e experiências prévias que fazem parte da formação social de boa parte de população brasileira vinculam-se ao modus operandi próprio do capitalismo - e uma vida de formação nesses moldes necessita de investimentos consistentes para possibilitar sua transformação.

Em seu caminho, o terapeuta ocupacional deve equilibrar-se de maneira tênue sobre diferentes papéis. Ao se propor a auxiliar o grupo em sua auto-organização, não pode ser chefe. Mesmo com ações dirigidas a estruturar o grupo, ao menos em primeiro momento, por meio de projetos de captação de recursos, da consolidação de 
parcerias interinstitucionais, da negociação de seu funcionamento, deve prestar atenção redobrada na verticalização das relaçóes - isso caso se vislumbre a construção de um empreendimento solidário. As falas proporcionam memórias que não devem ser esquecidas no cotidiano pragmático do grupo, reforçam a necessidade constante da formação em Economia Solidária.

Em nossa experiência, falas como as citadas por S2 mobilizaram a realizaçáo de encontros para abordar o tema da Economia Solidária, suas bases filosóficas e metodológicas, assim como a repercussão do capitalismo na vida humana. Além disso, frequentemente trabalhamos esses pontos no grupo e procuramos incentivar os participantes para a autogestão e para, a todo custo, formar os sujeitos para o exercício pragmático da Economia Solidária. Resgatamos: embora a declaração acima apresentada tenha sido proferida pelo sujeito mais recente no grupo, ela reforça a importância de realização de açôes continuadas e longitudinais de formação para a Economia Solidária.

Por sua vez, as vantagens e benefícios individuais tomados em detrimento do trabalho do grupo devem ser enfrentados pelo próprio coletivo em seu percurso à autogestão - o que náo desonera (e até mesmo reforça) o papel do terapeuta ocupacional como mediador nessa construção (CIA; CORTEGOSO, 2007). Para que a figura do chefe deixe de ser necessária é, contudo, imprescindível ampla responsabilidade de todos os participantes para com o grupo e para com suas tarefas.

Nesse horizonte pragmático, cabe ao papel do terapeuta ocupacional mediar e construir coletivamente, no mais fenomênico da Economia Solidária, contratuaçóes e modus operandi que proporcionem terreno para a edificaçáo da solidariedade - trabalho nada simples e em constante e singular elaboração.

Vale ressaltar, ainda neste momento, dois enunciados.

S1: É maravilhoso você trabalhar num lugar com pessoas que tem o mesmo problema que você. Você olha nos olhos deles e você se vê dentro dos olhos deles porque eles sentem o mesmo que você sente, e isso é maravilhoso... S1: Eu acho que essa igreja [adventista] faz muitas coisas sociais, quem sabe agora que nós estamos com as bolsas, quem sabe ir pedir "pra" vender nas igrejas, bazares e casa aberta e não sei... Chegar e falar que é de doentes mentais. Eu acho que eles vão ajudar! Ir no Mercadorama também. Agora vai chegar essa história da sacolinha. Vai sair sacolinha! Ir no supermercado falar que é uma ONG de pessoas com transtornos mentais, eu acho que se esconder nâo vai dar certo. É isso. Ver empresas grandes de comércio, pode ajudar. Eu acho que todo mundo está ligado em coisas assim, criança com câncer, deficiente físico, o mundo tá ligado nisso, então se você falar de transtornos mentais, eles vão querer ajudar. Se vocêse esconder náo vai ter muita ajuda!

Quanto ao grupo, existe inclinação [por parte dos terapeutas ocupacionais vinculados ao grupo] quanto à necessidade da ampliação da iniciativa para a populaçáo diversa, na premissa da instauração de espaço de convivência difusa e para fortalecimento da Economia Solidária de maneira geral e não somente de um dos guetos sociais, estratégia defendida por Singer (2001). Dois pontos, contudo, apresentam-se mister para subsidiar esta decisão: o primeiro diz respeito às barreiras da estrutura física da Associação, assim como o foco e a grande demanda da AAG para a atençáo aos usuários dos serviços de Saúde Mental; o segundo, e de prioridade, é que a decisão deve perpassar o aval do coletivo de trabalho, assim como qualquer outra decisão.

Em uma das falas acima, S1 pronuncia-se no sentido da defesa de realizar as vendas a partir da impressão do "rótulo" da loucura nos produtos, apelativo às vendas, segundo sua concepção. Alguns terapeutas ocupacionais e/ou profissionais da saúde poderiam tender a enxergar essa ação como estigmatização dos participantes do grupo. $\mathrm{Na}$ premissa de defender, acima de tudo, a autonomia dos indivíduos, afirmando que a qualidade dos produtos não necessita dessa vinculação para acontecer, o terapeuta ocupacional permitiria tal impressáo? Caberia ao terapeuta ocupacional posicionamento verticalizado e unidirecional quanto ao ponto?

A pergunta faz-se em contramáo: Cabe ao terapeuta ocupacional, mesmo que de maneira delicada, com utilização do vínculo e com o uso de todo o poder contratual que lhe é socialmente delegado, conduzir de maneira sorrateiramente simpática a decisão do grupo? Caberia ao terapeuta ocupacional em defesa daquela autonomia, surrupiar essa? Por que o faria?

Reafirma-se aqui a questão básica da autogestão democrática dos empreendimentos solidários. $\mathrm{O}$ terapeuta, como qualquer outro integrante do grupo, poderá ter voz e fala, caso sua vinculação ao grupo assim o permita, contudo, e acima de tudo, a igualdade e a democracia devem afirmar-se cotidianamente no grupo e em suas decisóes, por 
mais que desagradem alguns de seus participantes. Talvez reposicionamento profícuo do trabalho do terapeuta possa se dar no sentido de proporcionar acolhimento e contorno aos usuários frente às diferentes situaçôes a serem vivenciadas pelo grupo, advindas de seu processo decisório.

\section{Pragmática do Grupo de Geração de Trabalho e Renda em Saúde Mental: estratégias para o fortalecimento da iniciativa}

Ao responder a pergunta sobre como se deu sua chegada ao grupo de geração de trabalho e renda, S4 relata:

Ah, eu tava ali na clínica, no Centro Psiquiátrico Metropolitano (CPM), e daí pessoal daqui que me convidou.

Um ponto estratégico na abordagem do terapeuta ocupacional junto a grupos de geração de renda diz respeito ao ingresso de novos usuários no grupo. Alguns profissionais, muitas vezes tomando apoio em ideais da inclusão social, inserem novos indivíduos em grupos de geração de trabalho e renda por conta de encaminhamentos diversos realizados pelos serviços de Saúde Mental ou de assistência social ou até mesmo por buscas espontâneas.

Contudo, uma reflexão é imprescindível quando se trabalha na interface saúde e Economia Solidária: esses são empreendimentos voltados ao trabalho (GHIRARDI, 2004). Embora vínculo claro se apresente pelo conceito ampliado de saúde, pela diretriz da intersetorialidade e ainda sob a égide do conceito de inclusão social e do direcionamento da atual política pública de saúde mental, essas iniciativas pretendem instaurar espaços de pertencimento e participaçáo social das mais diversas populaçôes no trabalho.

O "convite" citado anteriormente foi realizado à usuária inicialmente por um dos usuários, por conta de uma demanda clara do grupo: Precisa-se de costureiras.

O grupo de geração de renda tinha na época diversas vagas de trabalho ocupadas por usuários que cortavam e vincavam os banners, faltavam, contudo, costureiras. Na contramão de uma possível e apressada alegaçáo sobre a importância da abertura do grupo a diversidades, em defesa de uma inclusão social romantizada, o grupo de trabalho tinha uma demanda específica para seu funcionamento.

Em reunião com o grupo, foi deliberado que novas vagas seriam abertas com exclusividade para a função de costura.

\section{S4: Lá perto de casa também tinha liceu de oficios, mas não tinha costura. Dai eu fui ali no SESC, fiz um mês e depois vim "pra" cá.. [...] Aprendi ali no SESC um pouquinho, dai as meninas me ensinaram como fazia a costura $d a$ bolsa, e ai fomos... Comecei naquelas pastinhas [...] costurei um monte de pastinha! E dai me ensinaram a fazer a bolsa.}

Ao terapeuta e ao próprio grupo caberia, nesse contexto, a clareza quanto à situaçáo do grupo como espaço vinculado ao trabalho. Faz-se premente a necessidade de pensar e organizar postos de trabalho e que o "seletivo" não seja exclusivamente pautado em questôes diagnósticas, encaminhamentos pautados na doença e/ou possibilidade de convivência em um grupo, mas sim que respondam às demandas próprias ao grupo no tocante à sua produção.

No caso da costureira S4, estruturamos uma busca sistemática por cursos de costura para que as ingressantes os pudessem realizar previamente ao seu ingresso no grupo. A participaçáo no curso poderia até mesmo contar como hora trabalhada, caso fosse de consenso do grupo.

\section{S5: $\dot{E}$, as pastas foram feitas, mais as bolsas que estão sendo "pra" venda... tem que resolver "pra" onde que vai vender, porque produção tá tendo, mas a venda não.}

Um posto de trabalho, advindo de outra necessidade do grupo, foi o de vendedor. O grupo buscou usuários com esse perfil, os quais foram encaminhados ao grupo. Reservamos até mesmo um acompanhamento terapêutico (AT) para um deles, que já tinha história pregressa nas vendas, mas que devido à doença, contudo, afastou-se do trabalho. Um dos objetivos do AT foi organizar junto com o usuário sua participaçáo no grupo como vendedor, procurando retomar um papel ocupacional que o usuário demonstrou interesse em resgatar (FERRO et al., 2014).

Embora a necessidade de preenchimento de postos de trabalho permeie as intervençóes do terapeuta ocupacional junto a grupos de geração de trabalho e renda, é importante afirmar e sustentar a transposição da frieza das relaçôes capitalistas. Ao invés de fechar portas a indivíduos que não tenham experiência na 
função, replicando funcionamento capitalista na seleção de sua mão de obra, é importante que os terapeutas ocupacionais procurem formas de viabilizar a participação de pessoas interessadas, seja a partir de vínculo com outras instituiçóes do seu território (a exemplo do curso no SESC), seja compondo formas de intervenção/dispositivos que possibilitem maximizar as potencialidades dos usuários para o exercício do cargo, como é o caso do acompanhamento terapêutico. Não se trata de inserir as pessoas no mundo do trabalho assumindo uma independência utópica, mas sim de proporcionar sistemas e funcionamentos solidários que possibilitem concretamente aos indivíduos, mesmo com limitaçóes diversas, advindas de condições de saúde, étnicas, etárias, sociais etc., sua participação, assumindo a diversidade em sua face mais pragmática.

\section{Geração de Trabalho e Renda: entre encaminhamento}

\section{e a estruturação concisa de projetos terapêuticos singulares}

O desfecho do subitem anterior permitiu a visualizaçáo ainda que breve da necessidade do trabalho em rede para fortalecer açóes junto aos grupos de geração de trabalho e renda. É necessário, contudo, maior aprofundamento.

Quando perguntamos sobre a forma pela qual tomaram conhecimento do grupo de geraçáo de trabalho e renda, $S 2$ e $S 5$ relataram:

\section{S2: Através do CAPS... A AAG mandou informaçōes "pra" lá, [...] eles mandavam uma carta por escrito para eu vir fazer uma entrevista. S5: Ah, [...] eu fiquei sabendo lá pelo Centro Psiquiátrico Metropolitano, pelo mural.}

Durante 2010 realizamos ampla divulgação das ações da Associação Arnaldo Gilberti nos mais diferentes CAPS do município, contando com flyers, divulgação por mailing e telefone. Diversos usuários chegaram à $\mathrm{AAG}$ com encaminhamentos assinados por profissionais da saúde, vinculados aos CAPS, boa parte constando somente a informação de seu CID, alguns poucos com algumas informaçóes adicionais, outros sem qualquer documento.

Diferentes documentos ressaltam o papel do CAPS na centralizaçâo e acionamento estratégico da rede de atenção territorial para a composição do Projeto Terapêutico Singular do usuário - novas portarias reafirmam legislativamente tal compromisso (BRASIL, 2011a, b; OLIVEIRA, 2007). Contudo, o que evidenciamos em praticamente todos os encaminhamentos que recebemos na AAG é o acionamento de pontos da rede sem qualquer conjugação concisa com o projeto terapêutico singular do usuário.

Vários usuários chegaram ao serviço com a recomendação de um profissional de que o usuário procurasse a Arnaldo Gilberti para fazer algo. Bem, mas por quê é necessária a insistência nesse ponto? Para o grupo de geração de trabalho e renda seria mister, para a ampliação de sua efetividade, maior proximidade com os CAPS da região.

Caso os usuários se apresentassem à AAG, ao grupo de geraçáo de trabalho e renda, com um projeto terapêutico bem delineado, com demanda clara de geraçáo de renda (por exemplo), acompanhados de seu técnico de referência, tanto a vinculação do usuário ao grupo como a resposta às suas necessidades seriam potencializadas. Caso o PTS direcionado ao usuário apresentasse, de antemáo ao contato com a AAG, conjugação estreita com suas demandas, contratuação de açóes entre técnicos dos CAPS, usuários e familiares, a participaçáo do usuário seria maximizada. Se o CAPS, a partir de contato próximo com o grupo de geraçáo de trabalho e renda da AAG, conhecesse a necessidade do grupo por costureiros, vendedores... a busca ativa de usuários com essas potencialidades/ vontades/histórias de vida, aliadas à demanda de geração de renda, potencializaria sobremaneira as açóes do grupo.

O CAPS é um dos equipamentos responsáveis pelo agenciamento da rede, por sua utilização estratégica, de modo a fortalecer os usuários, seus familiares e comunidade, no sentido de promover a inclusão social (BRASIL, 2004c, 2011a).

Se, por um lado, a prática do terapeuta ocupacional junto ao grupo de geração de trabalho e renda necessita do acionamento de uma rede de serviços, seja para projetos parceiros de formaçáo de pessoal (ao caso do curso de costura), seja para proporcionar escoamento aos produtos, seja para captação de recursos... a prática do terapeuta ocupacional vinculado ao CAPS (e não só do terapeuta ocupacional) necessita do movimento inverso: conhecer possibilidades diversas do território e conjugar tais potencialidades aos projetos terapêuticos dos usuários - a relação dialógica deve tomar corpo pragmático. Ações conjuntas e parcerias institucionais não podem ficar restritas à incipiência e impessoalidade do 
CID do usuário anotado em um papel com timbre institucional.

\subsection{Economia Solidária e o Grupo de Geração de Trabalho e Renda: entre fortalecimento e ideologia}

\begin{abstract}
S5: As pessoas não estão valorizando o trabalho de fazer bolsa, né? Ninguém valoriza isso. Acho que ninguém chegou a ganhar nem meio salário, metade de salário... $R \$ 200$ e pouco. Ninguém chega a ganhar isso. Eisso épouco, né? S1: O que tem de melhorar é que nós temos de achar uma saida... tem muita gente pobrezinha ali, eu também sou pobrezinha, de ganhar mais dinheiro, de achar mais local de vendas, quem sabe inventar outro produto. Não precisa ganhar muito dinheiro. O que a gente ganhar tá bom, mas se puder dar um passo a mais, melhor.
\end{abstract}

O subitem que se apresenta faz-se necessário para contemplar uma das grandes dificuldades evidenciadas nos mais diversos grupos de geração de trabalho e renda: a geração de renda. A questão é ampla e exige reflexão sobre diferentes prismas.

O grupo de geração de trabalho e renda deste estudo, como boa parte dos grupos com esse objetivo, apresenta geraçáo de renda bastante incipiente. A proposta da edificação da Economia Solidária ao usuário, por sua vez, é ousada e apresenta barreiras.

A problemática é ampla e vivenciada nacionalmente:

A partir dos princípios da economia solidária foram identificadas algumas características compartilhadas pelas cooperativas sociais mapeadas pelo SIES 2005-2007. Esses empreendimentos são em sua maioria organizaçóes informais e possuem uma articulaçáo considerável com movimentos de luta por direitos de cidadania, quando formalizados são registrados como associaçóes. [...] Quase a totalidade desses empreendimentos produz artefatos artesanais. Na maioria dessas cooperativas, os trabalhadores são remunerados por produto ou produtividade, com remuneração inferior a R \$100,00 (MARTINS, 2009, p. 162-163).

Para além, a problemática é ainda mais estrutural. Alguns dos usuários vinculados ao grupo aqui estudado possuíam benefícios sociais e previdenciários, os quais necessitavam, para sua manutenção, da afirmaçáo da impossibilidade para o usuário do exercício profissional. Embora o empenho dos agentes da saúde e dos participantes de grupos de geração de trabalho e renda possa se dar de maneira enfática a configuração de cooperativas sociais de trabalho, sua institucionalização esbarra legislativamente em alguns impasses. Pragmaticamente, como apresentar a seguinte proposta: "Querido usuário, desloque-se duas a três vezes por semana (no nosso caso) de sua casa para a AAG para ganhar a bagatela de $\mathrm{R} \$ 50,00$. Em mês gordo, pode ser que cheguemos a $\mathrm{R} \$ 200,00$, com esforço, em R \$ 300,00. Usuário, vamos montar uma cooperativa de trabalho? Abra máo de seu benefício para cair em um campo de incertezas quanto a seu salário mensal e sua subsistência".

A questão é apontada por Taleikis (2009, p. 241) e reitera a dificuldade para proporcionar subsídios para grupos de geração de trabalho e renda no campo da Saúde Mental:

Outra questão diz respeito à perda de benefícios previdenciários quando os usuários se tornam cooperados, passando à condição de segurado obrigatório da Previdência Social, o que inviabiliza a adesão dos usuários por receio de arriscar-se a perder tais benefícios.

Martins (2009, p. 150) reafirma tal questão ao expor, em sua análise, o caso da experiência do grupo de geração de trabalho e renda Trabalharte e sua configuração como associação:

Dois anos depois do primeiro contato com a incubadora ocorre a formalizaçáo do grupo, não como cooperativa, conforme planejado inicialmente, mas como associaçấo. [...] $\mathrm{O}$ que eliminou a possibilidade de formalizar o grupo como cooperativa foi o receio dos usuários de perderem seus benefícios sociais e previdenciários.

A autora ainda aponta:

Estes benefícios garantem uma renda básica de 1 salário-mínimo às pessoas com deficiência e idosos com mais de 65 anos. Este é um direito estabelecido pela Constituiçấo Federal de 1988 e regulamentado pela lei orgânica da assistência social (lei 8.742/1993 [alteraçóes dadas pelas leis 9.720/1998 e $12.435 / 2011]$ ), que tem como critério de concessão a renda familiar. Com o receio de perder esta renda, muitos beneficiários optam pelo trabalho informal. Outros tipos de benefícios tais como aqueles conferidos pela Previdência Social, como, por exemplo, a aposentadoria por invalidez, também contribuem com esta mesma situação. Este vínculo com o benefício apresenta 
dimensões objetivas e subjetivas. O benefício serve tanto para a subsistência do trabalhador quando para a manutenção de uma relação de dependência com o Estado. Além disso, é uma forma de reafirmar a situação de desvantagem e alimentar o estigma da incapacidade que identifica parte destes trabalhadores. Durante as visitas feitas pela pesquisadora a grupos organizados por pessoas com transtorno mental, o maior receio destes trabalhadores era justamente a falta de apoio financeiro e técnico na criaçáo e na manutençẫo destes empreendimentos. Esta situação acaba reforçando a manutenção dos benefícios sociais (MARTINS, 2009, p. 105).

Atualmente o corpo legislativo brasileiro prevê a existência de cooperativas sociais. Segundo a lei 9.867/99:

Art. $1^{\circ}$ As Cooperativas Sociais, constituídas com a finalidade de inserir as pessoas em desvantagem no mercado econômico, por meio do trabalho, fundamentam-se no interesse geral da comunidade em promover a pessoa humana e a integração social dos cidadãos, e incluem entre suas atividades: I - a organização e gestão de serviços sociossanitários e educativos; e II - o desenvolvimento de atividades agrícolas, industriais, comerciais e de serviços. (BRASIL, 1999, s.p.).

Contudo, a lei, em sua página única, não regulamenta com profundidade a forma de funcionamento da cooperativa social, nem prevê estímulos financeiros que possibilitem e/ou fomentem a implantação e estruturação dessa sorte de cooperativas ou sequer apresenta possibilidades de conjugação entre o empreendimento e os benefícios sociais percebidos por pessoas com transtorno mental (BRASIL, 1999).

Tal situação impóe quadro problemático aos profissionais e usuários envolvidos com grupos de geração de trabalho e renda em sua busca por estruturar a iniciativa como cooperativa de trabalho - e a proposta quanto à sua implantação, lançada ao usuário, ao qual cabe a opção benefício $\mathrm{X}$ cooperativa, apresenta qualidade praticamente única: recusável.

Embora as amarras apresentem-se, atualmente evidenciamos um grande movimento social para sua transposição. A II Conferência Nacional de Economia Solidária, realizada em 2010, apresenta enquanto demandas referentes às cooperativas sociais:
46. [...] c) garantir também que os benefícios de seguridade e proteção social dos integrantes das cooperativas sociais sejam preservados, pelo menos até que os ganhos do trabalho cooperativo sejam suficientes, em valor e regularidade que garanta o bem viver, para permitir sua dispensa, sendo a fiscalização realizada pelos respectivos conselhos municipais e estaduais. 47. [...]permissão para que as pessoas em desvantagem possam ser cooperativados, assegurando a manutenção do benefício no teto de até cinco salários-mínimos enquanto permanência na cooperativa social, o que requer a criação de um programa especial da previdência social para esses trabalhadores [...] (BRASIL, 2010b, p. 24-25).

Ainda, o relatório final da IV Conferência Nacional de Saúde Mental - intersetorial, realizada em 2010, aponta como necessidades:

838. Garantir a modificação da legislação para que os beneficiários do INSS com sofrimento psíquico possam desenvolver alguma atividade laboral que complemente sua renda, considerando-se as diretrizes da economia solidária, sem prejuízo do recebimento integral do seu benefício (BRASIL, 2010a, p. 135-136). 683. Garantir o Benefício de Prestação Continuada (BPC) aos usuários dos serviços de Saúde Mental, mesmo estando inseridos em cooperativas sociais. 684. Garantir a Seguridade Social aos participantes do cooperativismo social e mecanismos de incentivos com redução de impostos. (BRASIL, 2010a, p. 115). 193. Garantir a Economia Solidária como política pública nas três esferas de governo através: do reconhecimento e apoio aos projetos de incubação e trabalho que ocorrem nos equipamentos públicos de Saúde Mental; da regulação da lei de cooperativas sociais; da implantação de açôes estratégicas para fomentar as cadeias produtivas solidárias; da capacitaçáo dos empreendimentos de economia solidária para todas as etapas do processo produtivo; favorecer, por meio de incentivos, as cadeias produtivas solidárias e a disputa de mercado de consumo solidário; incentivar ponto de comércio justo e solidário (BRASIL, 2010a, p. 47).

A própria constituição e fortalecimento da Economia Solidária no panorama brasileiro vem se configurando de maneira processual, fruto de mobilizações diversas. Grandes marcos já citados, como a criação do Fórum Brasileiro de Economia 
Solidária e da Secretaria Nacional de Economia Solidária, assim como equipamentos e açôes diversas, como: financiamentos a baixo custo para empreendimentos solidários; a proliferação de incubadoras tecnológicas voltadas a dar suporte ao fortalecimento de cooperativas populares e iniciativas de geraçáo de trabalho e renda; organização de feiras de economia solidária, feiras de trocas e organização de redes de solidariedade; conquista de linhas temáticas específicas em editais de financiamento para práticas de Economia Solidária etc. começam a construir gradativamente suporte à Economia Solidária (CIA; CORTEGOSO, 2007; SOUZA, 2007).

Contudo, mesmo com tais investimentos, vale ressaltar uma experiência por nós vivenciada. Para dar suporte ao grupo em vários pontos, como: formação para a gestão solidária, marketing, estruturação de venda, cooperativismo etc., entramos, em 2010, em contato com uma incubadora tecnológica de cooperativas populares (ITCP) localizada em Curitiba, na Universidade Federal do Paraná. À época, havia um edital de chamamento para apoio a incubadoras para o trabalho junto a empreendimentos voltados à Saúde Mental, o qual previa um recurso de $\mathrm{R} \$ 5$ mil para os projetos aprovados. $\mathrm{O}$ coordenador, na ocasião, nos expôs a grande demanda de trabalho do ITCP e a inviabilidade de incubar outro projeto, acusando, para além, a quantia ínfima investida pelo edital.

Para estruturar inicialmente o grupo de geração de trabalho e renda, uma verba foi conseguida junto ao Fundo Diocesano de Solidariedade, o que possibilitou a compra de máquinas de costura, materiais de consumo e o pagamento de passagens aos participantes do grupo. Atualmente, contudo, a verba reservada ao pagamento de passagens, dado o encerramento do projeto do fundo Diocesano, foi cancelada pela Associação. Para a venda das bolsas, conseguimos uma barraca em um dos shoppings centers de Curitiba, contudo as vendas foram bastante restritas, o que inviabilizou sua continuidade. Atualmente, duas grandes encomendas foram alcançadas. Contudo, a incerteza quanto ao recebimento futuro de novos pedidos faz-se presente.

Martins (2009, p. 153-154), ao discorrer sobre a iniciativa de geraçáo de trabalho e renda Trabalharte, ainda relata:

Durante o período em que foram feitas visitas ao grupo, a cooperativa náo estava com nenhuma encomenda encaminhada, a produçáo estava praticamente parada. A comercialização dos produtos estava restrita à feira e ao próprio Centro de Convivência. Como as festas de final de ano estavam próximas, os cooperados esperavam que houvesse um incremento das vendas com a exposiçáo dos produtos da cooperativa em feiras e bazares natalinos. Segundo Mendes (2007, p. 122) é justamente nesse período de final de ano que as vendas aumentam na cooperativa, mesmo assim a renda dos trabalhadores não chega a um salário-mínimo.

Santos e Rodríguez (2002) e Mance (2002) apresentam a importância da destinação de açóes públicas e de esforço dos agentes envolvidos na Economia Solidária para a constituição e tecitura de Redes de Colaboração Solidária. Mance (2002, p. 1), ao argumentar sobre a noção de Redes de Colaboração Solidária, expõe tratar-se

[...]de uma estratégia para conectar empreendimentos solidários de produçáo, comercialização, financiamento, consumidores e outras organizaçóes populares (associações, sindicatos, ONGs etc.) em um movimento de realimentaçáo e crescimento conjunto, autossustentável, antagônico ao capitalismo.

O apoio mútuo, realizada por meio das Redes de Colaboração Solidária, pode proporcionar terreno fértil para o fortalecimento coletivo das iniciativas, as quais podem alicerçar-se de maneira parceira em todas as etapas do processo produtivo, seja na "comercialização de produtos ou ainda [n]a utilização coletiva de espaços de produçáo e maquinário" (MARTINS, 2009, p. 160).

Contudo, a edificação de tal rede exige intensa congregaçáo e articulaçáo entre as diferentes iniciativas locais de economia solidária e, com isso, o trabalho tanto do terapeuta ocupacional (ou dos apoiadores das iniciativas) quanto de seus participantes exige investimento tanto financeiro quanto de recursos humanos - o mapeamento, sistematização e divulgação dos empreendimentos solidários territoriais; a estruturação de feiras de troca, feiras de economia solidária e/ou bazares solidários; a conquista da participaçáo em feiras regulares ou mesmo de espaços para venda em pontos da cidade - conduzidos seja pelo grupo de geraçáo de trabalho e renda, seja por cooperativas parceiras de vendas; também a divulgação maciça dos ideais da economia solidária para a população, assim como sua capacitaçáo quanto ao tema, possibilitando-lhe a opção pelo direcionamento consciente de seu consumo, como investimento em práticas de economia solidária; a configuraçáo de estratégias criativas que possibilitem contato e 
interconsumo entre as iniciativas de geração de trabalho e renda são alguns exemplos de açôes que exigem investimento.

Algumas conquistas do movimento da Economia Solidária apresentam, ainda, como demanda ao poder público, a constituição de centros de comercialização voltados à Economia Solidária. A lei n. 3.039, de 5 de julho de 2005, é emblemática e, em seu artigo $5^{\circ}$, prevê:

XVI - instalação de centros de comércio e de feiras e articulaçáo de redes de agentes que promovam o consumo solidário e o comércio justo (MATO GROSSO DO SUL, 2005).

Para além, ainda, vale apresentar duas demandas presentes na IV Conferência de Saúde Mental Intersetorial e II Conferência Nacional de Economia Solidária que procuram proporcionar terreno de maior estabilidade para a expansão da Economia Solidária, demandando a potencialização tanto de condiçôes de produção, como de venda.

660. Introduzir na Lei de Licitaçóes (lei 8.666) critérios que possibilitem a participação dos empreendimentos de Economia Solidária da Saúde Mental e outros nos processos de compras públicas (BRASIL, 2010a, p. 112). 47. É preciso avançar também na constituição de uma nova legislação para o cooperativismo social, de forma a abranger todas as necessidades já identificadas e não contempladas pela lei $9867 / 99$, tais como: isenção de tributos; reconhecimento dos empreendimentos como de utilidade pública; articulação com o poder judiciário e o Ministério Público para o reconhecimento desses empreendimentos; inserção dos usuários da rede de Saúde Mental interditados civilmente nos EES como instrumento nos processos de suspensão de curatela; possibilidade de redução de pena mediante o trabalho do apenado em cooperativas sociais; criação de instrumentos legais nos estados e municípios que fomentem e apoiem a participaçáo das cooperativas sociais nos processos licitatórios; permissão para que as pessoas em desvantagem possam ser cooperativados, assegurando a manutenção do benefício no teto de até cinco salários-mínimos enquanto permanência na cooperativa social, o que requer a criaçáo de um programa especial da previdência social para esses trabalhadores; além de soluçóes para as necessidades que possam ser identificadas em grupo de trabalho interministerial, pactuando as políticas públicas de inclusão pelo trabalho (BRASIL, 2010b, p. 25).
Contudo, como campo de confluência política de interesses, esse processo é vagaroso e requer grande mobilização social no sentido de direcionar recursos públicos para o investimento nesse outro tipo de economia - o que reafirma a necessidade da destinação de investimento na formação para a Economia Solidária e para a mobilização política, já apresentada ao leitor anteriormente. $\mathrm{O}$ atual quadro social, logo, possibilita o aparecimento dos enunciados acima e outros tantos coletados nas entrevistas.

\section{S5: A impressão que eu tenho é que precisava que alguma autoridade ajudasse nisso, mas essa autoridade não quer colaborar "pra" fazer a venda das bolsas. Sempre tem uma pessoa superior a gente queprecisa da ajuda dele "pra" conseguir. Não sei que órgão, se é governo, se é prefeitura, mas não quer ajudar. entendeu? Eu acho que é isso. S2: Tinha que dar uma prioridade a nós se eles tivessem algum investimento a mais. Eles podiam procurar ajudar mais os... como diz, os microempresários, dar mais força para crescer. Mais geração de renda e mais emprego para as pessoas que precisam. É um incentivo a mais. S4: Ai eu vim aqui, falei com a Mônica. Ela disse "tá bem, só que a geração de renda não ganha muito". Falei "tudo bem, paga a passagem?", "paga", "tá bom".}

Para além do vislumbre do processo social de fortalecimento da Economia Solidária em âmbito nacional, é importante ressaltar aspectos nodais que permeiam tal proposta e que, inexoravelmente, constituem terreno arenoso para suas práticas.

Menezes (2007), em crítica à Economia Solidária, defende sua intrínseca e orgânica relação com os ideais do capitalismo, acusando até mesmo a alienaçáo do movimento. Para a autora, o oferecimento de subempregos a populaçóes em grande vulnerabilidade social, sob a falácia da criação de um mundo solidário, apresenta a pragmática sórdida da desmobilizaçáo do movimento operário, dificultando "...a criação de uma sociedade autônoma livre dos condicionamentos do Estado e do mercado" (MENEZES, 2007, p. 6). E o terapeuta ocupacional está imerso nesse processo histórico como um de seus agentes.

É necessário refletir sobre o papel do terapeuta ocupacional nessas iniciativas, procurando compor açôes políticas para transformação macroestrutural congregadas com a estruturação da iniciativa em si: seja por meio da organizaçáo e fomento à participação política de representantes das cooperativas e/ou grupos de geração de trabalho e 
renda nos espaços democráticos decisórios; seja por meio da composiçáo com vereadores e deputados no terreno legislativo, para suporte diverso às iniciativas de geração de trabalho e renda; seja pela organização de grupos politicamente engajados para cobrar açóes públicas que operacionalizem as conquistas legislativas; seja por meio da sistematização e organização de uma rede regional de solidariedade...

O percurso da linha tênue, de um lado agente de manutenção do capitalismo, de outro agente mobilizador social para a edificação da Economia Solidária, exige elucidação sobre a navalha desse caminhar e, acima de tudo, açóes concretas para compor enfrentamentos políticos necessários para a consolidação da solidariedade que se pretende.

S1: Ah, eles [o grupo] podem ajudar em tudo. Eles são a razão de eu conseguir isso. Sem eles eu não vou conseguir. Sozinha eu não vou conseguir. Por isso eu me desesperei nesse final de ano e tomei mais remédio quando falaram que a Associação ia acabar. Porque sem eles eu não sou nada, esse que é o problema. Sozinha eu não vou conseguir, eu acho.

\section{Conclusões}

A interface Terapia Ocupacional e Economia Solidária exige açôes das mais diversas ordens para fazer dos ideais da inclusão social e da solidariedade pragmáticas cotidianas. Permeia a estruturação de iniciativas de geração de trabalho e renda a construção de modus operandi pautados na gestáo democrática e apoio mútuo; mediação de conflitos e contratuaçôes; organização estratégica da rede de atenção e da rede de colaboração solidária; a responsabilização e elaboração de projetos terapêuticos concisos; a mobilização política de diferentes agentes sociais e sua representatividade, assim como enfrentamentos políticos constantes e a edificaçâo legislativa que proporcionem suporte às iniciativas pautadas na Economia Solidária.

\section{Referências}

AZAMBUJA, L. R. Os valores da economia solidária. Sociologias, Porto Alegre, n. 21, p. 282-317, 2009.

BRASIL. Lei $\mathrm{n}^{\circ}$ 9.867, de 10 de novembro de 1999. Dispóe sobre a criaçáo e o funcionamento de Cooperativas Sociais, visando à integração social dos cidadãos, conforme especifica. Diário Oficial da União, Poder Executivo, Brasília, DF, 11 nov. 1999. Disponível em: <http://www.planalto.gov.br/ccivil_03/Leis/L9867. htm>. Acesso em: 10 set. 2014.
BRASIL. Decreto $n^{\circ} 4.764$, de 24 de junho de 2003. Aprova a Estrutura Regimental e o Quadro Demonstrativo dos Cargos em Comissáo e das Funçóes Gratificadas do Ministério do Trabalho e Emprego, e dá outras providências. Diário Oficial da Uniāo, Poder Executivo, Brasília, DF, 25 jun. 2003. Disponível em: <http://www.planalto.gov.br/ccivil_03/ decreto/2003/D4764.htm>. Acesso em: 20 ago. 2014.

BRASIL. Ministério da Saúde. Legislação em saúde mental: 1990-2004. 5. ed. Brasília: Ministério da Saúde, 2004a. Disponível em: <http://www.aadom.org. $\mathrm{br} /$ materiais-de-apoio/assistencia-em-saude-mental>. Acesso em: 20 ago. 2014.

BRASIL. Decreto n ${ }^{\circ} 5.063$, de 3 de maio de 2004. Aprova a Estrutura Regimental e o Quadro Demonstrativo dos Cargos em Comissão e das Funções Gratificadas do Ministério do Trabalho e Emprego, e dá outras providências. Diário Oficial da União, 4 maio 2004b. Disponível em: <http://www.planalto.gov. br/ccivil_03/_Ato2004-2006/2004/Decreto/D5063. htm\#art6>. Acesso em: 20 dez. 2014.

BRASIL. Ministério da Saúde. Saúde mental no SUS: os centros de atenção psicossocial. Brasília: Ministério da Saúde, 2004c. Disponível em: <http://www.aadom. org.br/materiais-de-apoio/assistencia-em-saude-mental> Acesso em: 20 ago. 2014.

BRASIL. Ministério da Saúde. Saúde mental e economia solidária: inclusão social pelo trabalho. Brasília: Ministério da Saúde, 2006.

BRASIL. Ministério da Saúde. Conselho Nacional de Saúde. Relatório Final da IV Conferência Nacional de Saúde Mental - Intersetorial, 27 de junho a 1 de julho de 2010. Brasília: Conselho Nacional de Saúde Conselho Nacional de Saúde, 2010a. Disponível em: <http://conselho.saude.gov.br/biblioteca/Relatorios/ relatorio_final_IVcnsmi_cns.pdf>. Acesso em: 10 set. 2014.

BRASIL. Ministério do Trabalho e Emprego. II Conferência Nacional de Economia Solidária-CONAES. Relatório Final. Brasília, 2010b. Disponível em: <http:// portal.mte.gov.br/data/files/8A7C812D36A28000013 731C8C25D7CEE/II_coanes_documento_final.pdf>. Acesso em: 10 set. 2014.

BRASIL. Ministério da Saúde. Portaria nº 3.088, de 23 de dezembro de 2011. Institui a Rede de Atençáo Psicossocial para pessoas com sofrimento ou transtorno mental e com necessidades decorrentes do uso de crack, álcool e outras drogas, no âmbito do Sistema Único de Saúde (SUS). Diário Oficial da União, 26 dez. 2011a. Disponível em: <http://www.aadom.org.br/materiaisde-apoio/legislacao-em-saude-mental>. Acesso em: 6 ago. 2012

BRASIL. Ministério da Saúde. Guia prático de matriciamento em saúde mental. Brasília: Ministério da saúde, 2011b. Disponível em: <http://www.aadom.org. $\mathrm{br} / \mathrm{materiais-de-apoio/assistencia-em-saude-mental/>.}$ Acesso em: 1 set. 2014. 
BRASIL. Ministério da Saúde. Portaria n 132, de 26 de janeiro de 2012. Institui incentivo financeiro de custeio para desenvolvimento do componente Reabilitação Psicossocial da Rede de Atençáo Psicossocial do Sistema Único de Saúde (SUS). Diário Oficial da União, 26 jan. 2012. Disponível em: <http://www.aadom.org.br/ materiais-de-apoio/legislacao-em-saude-mental $>$. Acesso em: 1 set. 2014.

CASTANHEIRA, M. E. M.; PEREIRA, J. R. Ação coletiva no âmbito da economia solidária e da autogestão. Revista Katálysis, Florianópolis, v. 11, n. 1, p. 116-122, 2008.

CAVEDON, N. R.; FERRAZ, D. L. S. "Tricotando as redes de solidariedade": as culturas organizacionais de uma loja autogestionada de economia popular solidária de porto alegre. Organizaçóes \& Sociedade, Salvador, v. 13, n. 39, p. 93-111, 2006. http://dx.doi.org/10.1590/ S1984-92302006000400006

CIA, F.; CORTEGOSO, A. L. Condutas de mediadores em processos de decisão coletiva como condição para uma educação emancipatória na economia solidária. Psicologia \& Sociedade, Belo Horizonte, v. 19, n. 2, p. 103-113, 2007.

COUTINHO, M. C. et al. Novos caminhos, cooperação e solidariedade: a psicologia em empreendimentos solidários. Psicologia \& Sociedade, Belo Horizonte, v. 17, n. 1, p. 17-28, 2005.

FERRO, L. F. et al. Grupo de Convivência em Saúde Mental: perspectivas de usuários e a experiência do curso de Terapia Ocupacional da Universidade Federal do Paraná. Revista de Terapia Ocupacional da Universidade de São Paulo, São Paulo, v. 23, n. 2, p. 146-152, 2012.

FERRO, L. F. et al. Demandas, subjetividade e processo terapêutico: construçóes e limitaçóes do acompanhamento terapêutico. Cadernos de Terapia Ocupacional da UFSCar, São Carlos, v. 22, n. 3, p. $1-11,2014$

FONSECA, M. A. A Prática do Terapeuta Ocupacional em saúde mental a partir de uma perspectiva não excludente e de respeito às diferenças. In: DRUMOND, A. F.; REZENDE, M. B. (Org.). Intervenções da Terapia Ocupacional. Belo Horizonte: Editora UFMG, 2008. p. 71-94.

FÓRUM BRASILEIRO DE ECONOMIA SOLIDÁRIA - FBES. O Fórum Brasileiro de Economia Solidária: histórico. Brasília. Disponível em: <http:// www.fbes.org.br/index.php?option=com_content\&tas k=view\&id=61\&Itemid=57>. Acesso em: 20 ago. 2014.

GHIRARDI, M. I. G. Trabalho e deficiência: as cooperativas como estratégia de inclusão social. Revista de Terapia Ocupacional da Universidade de São Paulo, São Paulo, v. 15, n. 2, p. 49-54, 2004.

LEITE, M. P. A economia solidária e o trabalho associativo: teorias e realidades. Revista Brasileira de Ciências Sociais, São Paulo, v. 24, n. 69, p. 31-51, 2009. http://dx.doi.org/10.1590/S0102-69092009000100003

LOPES, R. E.; LEÃO, A. Terapeutas ocupacionais e os centros de convivência e cooperativas: novas açôes de saúde. Revista de Terapia Ocupacional da Universidade de São Paulo, Sáo Paulo, v. 13, n. 2, p. 56-63, 2002.

LUSSI, I. A. O.; MATSUKURA, T. S.; HAHN, M. S. Reabilitação psicossocial: oficinas de geração de renda no contexto da saúde mental. O Mundo da Saúde, São Paulo, v. 34, n. 2, p. 284-290, 2010.

MANCE, E. A. Redes de Colaboração Solidária. Petrópolis: Vozes, 2002. Disponível em: <http://www. solidarius.com.br/mance/biblioteca/redecolaboracao-pt. pdf>. Acesso em: 10 ago. 2014.

MARCONI, M. A.; LAKATOS, E. M. Fundamentos de metodologia cientifica. 6. ed. São Paulo: Atlas, 2007.

MARTINS, R. C. A. Cooperativas sociais no Brasil: debates e práticas na tecitura de um campo em construção. 2009. 193 f. Dissertação (Mestrado em Sociologia)-Universidade de Brasília, Brasília, 2009.

MATO GROSSO DO SUL. Lei n ${ }^{\circ} 3.039$, de 5 de julho de 2005. Institui o Programa Estadual de Fomento à Economia Solidária de Mato Grosso do Sul - PEFES/ MS, e dá outras providências. Diário Oficial do Estado do Mato Grosso do Sul, Campo Grande, MS, jul. 2005. Disponível em: <http://www.cpisp.org.br/htm/leis/page. aspx?LeiID=98>. Acesso em: 8 ago. 2014.

MENEZES, M. T. C. G. Economia Solidária: elementos para uma crítica marxista. In: JORNADA INTERNACIONAL DE POLÍTICAS PÚBLICAS, 3., 2007, São Luís. Anais... São Luís: UFMA, 2007.

MINAYO, M. C. S. (Org.). Pesquisa social: teoria, método e criatividade. 22. ed. Rio de Janeiro: Vozes, 2003.

NARDI, H. C.; YULES, D. B. Transformaçôes contemporâneas do trabalho e processos de subjetivação: os jovens face à nova economia e à economia solidária. Estudos de Psicologia, Natal, v. 10, n. 1, p. 95-103, 2005. http://dx.doi.org/10.1590/S1413-294X2005000100011

OLIVEIRA, G. N. O Projeto terapêutico como contribuição para a mudança das práticas de saúde. 2007. 202 f. Dissertação (Mestrado em Saúde Coletiva)Universidade Estadual de Campinas, Campinas, SP, 2007.

OLIVEIRA, P. S. Raízes solidárias: a economia, a cultura e as pessoas. In: BRUHNS, H. T.; GUTIERREZ, G. L. Representaçóes do lúdico. Campinas: Autores Associados, 2001. p. 43-57.

RIBEIRO, M. B. S.; OLIVEIRA, L. R. Terapia Ocupacional e saúde mental: construindo lugares de inclusão social. Interface: Comunicação, Saúde, Educação, Botucatu, v. 9, n. 17, p. 425-31, 2005.

SANTOS, B. S.; RODRÍGUEZ, C. Para ampliar o cânone da produção. In: SANTOS, B. S. (Org.). Produzir para viver: os caminhos da produçáo náo capitalista. Rio de Janeiro: Civilização Brasileira, 2002. p. 23-64.

SILVA, M. K.; OLIVEIRA, G. L. Solidariedade assimétrica: capital social, hierarquia e êxito em um empreendimento de "economia solidária". Revista Katálysis, Florianópolis, v. 12, n. 1, p. 59-67, 2009.

SINGER, P. Autogestão e socialismo: oito hipóteses sobre a implantação do socialismo via autogestão. In: 
OLIVEIRA, P. S. O lúdico na cultura solidária. São Paulo: Hucitec, 2001. p. 229-239.

SINGER, P. Saúde mental e economia solidária. In: MINISTÉRIO DA SAÚDE. Saúde mental e economia solidária: inclusão social pelo trabalho. Brasília: Editora do Ministério da Saúde, 2005. p. 11-12.

SOUZA, A. R. Igreja Católica e Mercados: a ambivalência entre a solidariedade e a competição. Religião e Sociedade, Rio de Janeiro, v. 27, n. 1, p. 156-174, 2007.
SOUSA, D. N. Reestruturação capitalista e trabalho: notas críticas acerca da economia solidária. Revista Katálysis, Florianópolis, v. 11, n. 1, p. 53-60, 2008.

TALEIKIS, P. U. O trabalho como estratégia de desinstitucionalização e emancipação na saúde mental. 2009. 281 f. Dissertação (Mestrado em Enfermagem)Universidade de São Paulo, São Paulo, 2009.

YIN, R. K. Estudo de caso: planejamento e métodos. 4. ed. Porto Alegre: Bookman, 2010.

\section{Contribuição dos Autores}

Luís Felipe Ferro coordenou a pesquisa, participou na concepção e redação do texto, na análise dos dados e na organização de fontes. Mônica Macedo participou na concepção e redação do texto, revisão e organização de fontes. Morgana Bardemaker Loureiro participou da coleta e análise dos dados, revisão e organização de fontes. Todos os autores aprovaram a versão final do artigo.

\section{Notas}

${ }^{1}$ Material é parte integrante da pesquisa "ACOLHIMENTO ENQUANTO FERRAMENTA ESTRATÉGICA PARA A ESTRUTURAÇĀO DE PROPOSTAS DE GERAÇÃO DE TRABALHO E RENDA EM SAÚDE MENTAL”, aprovada pelo Comitê de Ética em Pesquisa (CEP/UFPR) sob o número 1074.199.10.12. Todos os procedimentos éticos foram seguidos. 